\title{
Democracia Agonística por Oposição ao Narcisismo Político: contra o Ódio como forma de Fazer Política
}

\author{
Agonistic Democracy as Opposed to Political \\ Narcissism: against Hatred as a way of Doing Politics
}

\section{Democracia Agonista frente al Narcisismo Político: contra el odio como forma de Hacer Política}

José Ricardo Cunha*

\begin{abstract}
1 Introdução. 2 Egocentrismo, egoísmo e a negação do outro: a política como ódio. 3 Democracia Agonística e o outro como adversário e não como inimigo. 4 Considerações finais. Referências.
\end{abstract}

\section{RESUMO}

Objetivo: $\mathrm{O}$ presente artigo tem como objetivos: 1) apontar como o egocentrismo e o egoísmo constituem uma cultura de fundo que inviabiliza a política democrática e, no limite, corroboram o ódio como forma de fazer política; e 2) indicar a democracia agonística, como proposta por Chantal Mouffe, a partir de um debate com Carl Schmitt, como uma forma de fazer política mais consentânea com o pluralismo e, portanto, com o assentimento da alteridade como constitutiva do próprio fazer político.

Metodologia: Para alcançar os objetivos propostos, o artigo apoia-se no método hipotético-dedutivo, mediante a pesquisa bibliográfica em textos que tratam sobre o tema.

Resultados: Individualidade e pluralismo são características centrais do mundo moderno. Contudo, a afirmação excessiva da individualidade produziu situações em que se busca suplantar o pluralismo em nome do sectarismo. Uma cultura de fundo de reforço do ego parece descambar em muitos momentos para um forte egocentrismo e um individualismo brutal. No aspecto político, isso institui práticas alérgicas à alteridade

\footnotetext{
"Doutor em Direito pela Universidade Federal de Santa Catarina. Professor associado da Faculdade de Direito da Universidade do Estado do Rio de Janeiro. Atua na Pós-Graduação em Direito, na Linha de Pesquisa em Teoria e Filosofia do Direito, e na Graduação em Direito da Faculdade de Direito da UERJ. Universidade do Estado do Rio de Janeiro, Rio de Janeiro, RJ, Brasil. E-mail: <jrcunha@uol.com.br>.http://orcid.org/0000-0002-8737-7892
} 
que chegam a suplantar o próprio compromisso com a democracia, abrindo espaço para o ódio como forma de fazer política. Em oposição a essa perspectiva, o artigo indica o modelo agonístico de democracia, conforme sustentado por Chantal Mouffe. Em diálogo com Carl Schmitt, Mouffe defende que a política democrática é um campo de inevitável conflito, todavia esse conflito não deve se dar na forma de um antagonismo onde aquele que pensa diferente seja tomado como um inimigo a ser destruído. No lugar do antagonismo, propõe o agonismo, que significa um permanente embate democrático, porém em condições nas quais o outro não seja visto como inimigo, mas sim como adversário.

Palavras-chave: egocentrismo; narcisismo político; antagonismo; democracia agonística; Chantal Mouffe.

\section{ABSTRACT}

Objective: This article aims to: 1) point out how self-centeredness and selfishness are a fundamental culture that makes democratic politics unfeasible and, ultimately, corroborates hatred as a way of doing politics; and 2) to indicate agonistic democracy, as proposed by Chantal Mouffe, from a debate with Carl Schmitt, as a way of making politics more in line with pluralism and, therefore, with the assent of otherness as constitutive of political making itself.

Methodology: To achieve the proposed objectives, the article is based on the hypothetical-deductive method, through bibliographic research in texts dealing with the theme.

Results: Individuality and pluralism are central features of the modern world. However, the excessive assertion of individuality has produced situations in which an attempt is made to supplant pluralism in the name of sectarianism. A background culture of ego reinforcement seems to fall into many moments towards a strong egocentricity and a brutal individualism. In the political aspect, this institutes practices allergic to otherness that go beyond the commitment to democracy, opening space for hatred as a way of doing politics. In opposition to this perspective, the article indicates the agonistic model of democracy, as supported by Chantal Mouffe. In dialogue with Carl Schmitt, Mouffe argues that democratic politics is a field of inevitable conflict, however this conflict must not take the form of an antagonism where the one who thinks differently is taken as an enemy to be destroyed. Instead of antagonism, it proposes agonism, which means a permanent democratic struggle, but in conditions in which the other is not seen as an enemy, but as an adversary.

Keywords: egocentrism; political narcissism; antagonism; agonistic democracy; Chantal Mouffe.

\section{RESUMEN}

Objetivo: Este artículo tiene como objetivo: 1) señalar cómo el egocentrismo y el egoísmo constituyen una cultura de fondo que vuelve inviable la política democrática y, 
en el límite, corrobora el odio como forma de hacer política; y 2) señalar la democracia agonista, como propone Chantal Mouffe, a partir de un debate con Carl Schmitt, como una forma de hacer la política más acorde con el pluralismo y, por tanto, con el asentimiento de la alteridad como constitutivo de la propia acción política.

Metodología: Para lograr los objetivos propuestos, el artículo se basa en el método hipotético-deductivo, mediante la búsqueda bibliográfica en textos que abordan el tema.

Resultados: la individualidad y el pluralismo son características centrales del mundo moderno. Sin embargo, la afirmación excesiva de la individualidad ha producido situaciones en las que se intenta suplantar el pluralismo en nombre del sectarismo. Una cultura de trasfondo que refuerza el ego a menudo parece deslizarse hacia un fuerte egocentrismo y un individualismo brutal. En el aspecto político, este instituto practica prácticas alérgicas a la alteridad que vienen a suplantar el compromiso con la democracia misma, dando lugar al odio como forma de hacer política. En oposición a esta perspectiva, el artículo señala el modelo agonista de democracia, apoyado por Chantal Mouffe. En diálogo con Carl Schmitt, Mouffe sostiene que la política democrática es un campo de conflicto inevitable, sin embargo, este conflicto no debe tomar la forma de un antagonismo donde aquellos que piensan de manera diferente son tomados como un enemigo a destruir. En lugar del antagonismo, propone el agonismo, que significa una lucha democrática permanente, pero en condiciones en las que el otro no es visto como un enemigo, sino como un adversario.

Palabras clave: egocentrismo; narcisismo político; antagonismo; democracia agonista; Chantal Mouffe.

\section{INTRODUÇÃO}

A política democrática implica a capacidade de autogoverno e de decisão coletiva. Envolve a realização de escolhas públicas dentro do limite do respeito aos direitos fundamentais. Nesses termos, diferentes concepções de bem são chamadas a conviver a partir de um conceito público de justiça balizado em uma constituição legítima. Dito assim, pode até parecer que, na teoria, está tudo muito bem resolvido e consolidado, mas é só uma aparência. Na literatura especializada, existem grandes debates e controvérsias sobre o conceito e o estatuto da democracia ${ }^{1}$ e parece não haver uma razão definitiva para se achar que podemos chegar em breve a um consenso teórico sobre o assunto. Além disso, os debates em torno da democracia também envolvem problemas sobre a relação entre teoria democrática e prática democrática ${ }^{2}$, problemas que, em certos momentos, sugerem um descompasso mais ou menos global entre esses dois planos e, em outros momentos, sugerem algum tipo de crise do modelo democrático.

\footnotetext{
${ }^{1}$ A título de exemplo, vejam-se os representativos trabalhos: (ARMONY; SCHAMIS, 2005; HELD, 1995)

${ }^{2}$ A título de exemplo, vejam-se os representativos trabalhos: (PRZEWORSKI, 2019; TAYLOR, 2019). 
Seja como for, a democracia é sempre um tema relevante e nunca é demais um esforço de análise, crítica e reflexão.

O presente artigo não pretende fazer uma análise conceitual ou global da democracia. Sua proposta é mais modesta e específica. Parte do suposto de que a modernidade é um tempo de reforço do ego, mas que tal reforço descambou, em muitos casos, para um egoísmo que impede ou dificulta a relação com o outro e o respeito por diferentes concepções de bem e, até mesmo, sobre o que seja uma sociedade razoavelmente justa. Isso enfraquece a democracia e resulta em um cenário político instável e pouco propício ao diálogo, o que é potencializado por agressões de diferentes tipos que são perpetradas nos ambientes das redes sociais. Nesse contexto, o artigo tem os objetivos simples, mas não triviais, de 1) apontar como o egocentrismo e o egoísmo constituem uma cultura de fundo que inviabiliza a política democrática e, no limite, corroboram o ódio como forma de fazer política; e 2) indicar a democracia agonística, como proposta por Chantal Mouffe, a partir de um debate com Carl Schmitt, como uma forma de fazer política mais consentânea com o pluralismo e, portanto, com o assentimento da alteridade como constitutiva do próprio fazer político.

O conceito de democracia agonística, embora não tenha tido tanta influência na teoria política contemporânea quanto outros conceitos, como de democracia deliberativa, por exemplo, encontrou novos espaços analíticos nas tensões crescentes do mundo globalizado, especialmente a partir da onda conservadora representada por governos como de Trump, Orbán e Bolsonaro, ou, ainda, em movimentos como o Brexit. $^{3} \mathrm{O}$ crescimento da influência de uma extrema-direita com perfil agressivo e truculento deixou mais que clara a importância de se pensar as diferenças típicas do pluralismo moderno em termos que não sejam tóxicos à alteridade. Para a democracia agonística, não cabe lidar com as diferenças e os embates decorrentes do pluralismo a partir de rótulos como "racionalidade" ou "consenso", contudo também não cabe supor que identidades comunais ou sentimentos de pertença irão resolver os impasses do próprio pluralismo (PAXTON, 2020). Se, por um lado, a democracia agonística supõe a ideia de contestação política como constitutiva da democracia, por outro lado, também assume que a interdependência também o é (PAXTON, 2020). Então, é urgente e necessário dar-se conta dos processos sociais da cultura de fundo que inflam a subjetividade de forma incontida e, por isso, produzem uma arrogância e uma ilusão de autossuficiência que são extremamente nocivas à democracia.

\footnotetext{
${ }^{3}$ Cf. https://en.wikipedia.org/wiki/Brexit. Acesso em: 12 maio 2021.
} 


\title{
2 EGOCENTRISMO, EGOÍSMO E NEGAC̣ÃO DO OUTRO: A POLÍTICA COMO ÓDIO
}

Sergio Paulo Rouanet nos recorda que o projeto da modernidade está baseado em três elementos fundamentais: universalidade, individualidade e autonomia. Nas palavras de Rouanet (1993, p. 9):

\begin{abstract}
A universalidade significa que ele visa todos os seres humanos, independentemente de barreiras nacionais, étnicas ou culturais. A individualidade significa que esses seres humanos são pensados como pessoas concretas e não como integrantes de uma coletividade e que se atribui valor ético positivo à sua crescente individualização. A autonomia significa que esses seres humanos individualizados são aptos a pensarem por si mesmos, sem a tutela da religião ou da ideologia, a agirem no espaço público e a adquirirem pelo seu trabalho os bens e serviço necessários à sobrevivência material.
\end{abstract}

Dessas três perspectivas apresentadas por Rouanet, aquela que parece ter se afirmado com maior força, sem dúvida, é a da individualidade. Isso porque a universalidade é enfraquecida por profundas diferenças culturais e a autonomia é enfraquecida por processos econômicos que geram a precarização da vida de incontáveis pessoas. Já em relação à individualidade, como disse o autor, há uma crescente individualização no mundo atual. De certa forma, isso se conecta ao fato de que a modernidade triunfante é o tempo do sujeito e da razão, ou do sujeito racional, isto é, aquele que é capaz de calcular, no plano das ciências, e discernir, no plano da moralidade (TOURAINE, 1994). O sujeito racional é o sujeito potente para se afirmar a si mesmo e se instituir como referência para o mundo. Na modernidade, sujeito não é aquele que está sujeito a algo, mas, sobretudo, aquele que pratica a ação, aquele que se estabelece e assenta um espaço.

Toda essa confiança na potência do sujeito, o que, sem dúvida, é uma coisa boa, acabou por estimular uma exacerbação da individualidade que, por seu turno, incitou a produção de uma cultura de fortalecimento do ego, que pode trazer consequências que não são tão boas. Isso funciona de uma forma como se as potências do sujeito fizessem mais sentido ou tivessem mais valor quando fossem destinadas a ele mesmo, aos seus próprios interesses e não ao bem comum. O senso comum afirma e repete pensamentos do tipo: "para ajudar o outro, você tem de primeiro ajudar você", "só coloca ordem no mundo quem antes coloca ordem na própria casa", "se você não se ajudar, ninguém vai ajudar você", "você tem que ser alguém na vida" etc... Há um caldo de cultura que reforça o foco no ego, gerando um grande egocentrismo que se instala na vida de boa parte das pessoas, como se fosse algo necessário e bom. Muito mais do que a ajuda, se propala a autoajuda. Essa é consumida como se fosse a solução de todos, ou quase todos, problemas de cada um de nós. Inclusive para problemas coletivos, um número significativo de pessoas tende a 
procurar soluções individuais, porque não enxergam as necessidades dos outros como tão importantes quanto às suas próprias necessidades. Nos livros Sociedade do Cansaço (HAN, 2015) e Topologia da Violência (HAN, 2017), Byung-Chul Han nos mostra como o mundo moderno se torna crescentemente individualista sugerindo que cada um detém os meios de produção e reprodução de si mesmo. Para o autor, essa fragmentação associada a uma afirmação de si engendra formas de violência que são sutis e indiretas e que contribuem para o aprofundamento do próprio individualismo e da perda da noção do comum.

Como aprendemos na tradição filosófica, de Aristóteles a Kant, a razão humana, uma das bases mais importantes da potência do sujeito, deve operar tanto na chave do racional quanto na chave do razoável. Uma pessoa racional é aquela que é capaz de estabelecer relações de causalidade, fazer cálculos, elaborar planos para pôr em prática as ações que visam à realização de seus interesses e à concretização de suas próprias concepções de bem. Já uma pessoa razoável é aquela que consegue avaliar as próprias atitudes a partir de como tais atitudes podem afetar as demais pessoas. A razoabilidade implica a aceitabilidade de algo a partir do lugar ocupado pelos outros. Portanto, uma conduta pode ser racional, mas não ser razoável. Uma pessoa pode planejar meticulosamente uma ação que interessa aos seus propósitos, mas que agride concepções de bem distintas da sua ou, até mesmo, que viola direitos alheios. O fato é que a modernidade se destacou pela afirmação de um sujeito racional, mas permanece sendo um desafio à prática de condutas razoáveis, que levem em conta a pluralidade de interesses legítimos e a figura do outro como alguém que merece minha consideração. $\mathrm{O}$ egocentrismo disseminou o egoísmo como um fundamento lídimo para a vida social. Pensar em si mesmo antes do outro é um padrão pouco questionado, já o altruísmo é visto, em geral, com certa desconfiança, como se fosse típico de pessoas tolas ou ingênuas. A caridade segue sendo pregada, mas a partir daquilo que sobra, isto é, doar os bens que me sobram e o tempo que me sobra. Isso é o máximo que o outro merece de mim: minhas sobras.

O egocentrismo me afasta dos outros e o egoísmo faz que o outro seja visto como uma ameaça, como alguém que pode tomar aquilo que é meu ou que eu julgo que deveria ser meu, seja este "aquilo" considerado como um bem, um direito, um prazer ou uma pessoa. Para o egoísmo, é o meu bem, o meu direito e o meu prazer que devem prevalecer; para o egoísta, as demais pessoas devem estar a serviço de suas vontades. Tudo isso produz uma brutal desvalorização do lugar do outro, da outricidade, pois o outro perde sua dignidade própria diante de um eu agigantado. Trata-se de um esvanecimento da capacidade de levar o outro em consideração, a não ser que eu tenha algum tipo de relação especial ou privilegiada com esse outro. Porém, nesse caso da relação privilegiada, o outro me interessa pelo que ele pode me proporcionar, seja algo 
material, seja imaterial. O problema, propriamente dito, é que o lugar da outricidade vai se perdendo, como se ali já não houvesse mais uma dignidade intrínseca. No mundo presente, não falta humanismo, o que nos falta, como disse Lévinas, é o humanismo do outro homem (LÉVINAS, 2012).

Nesse cenário, algumas características pessoais ou tipos de conduta vão se tornando cada vez mais comuns ou difundidas. Numa cultura de profundo fortalecimento do ego e de brutal desvalorização da outricidade, vai se tornando corriqueiro ver pessoas que: nada lhes importa mais do que a si mesmas; afirmam o seu estilo de vida como o correto para todos; não são capazes de se colocar no lugar do outro; rechaçam aqueles que pensam de forma diferente; menosprezam os argumentos divergentes; não têm paciência para ouvir outras opiniões e elevam o tom de voz para afirmar a própria opinião; inventam ou propagam mentiras desabonadoras sobre aqueles dos quais divergem; somente sentem alegria e tristeza pelo outro quando esse outro é sentido como um igual. Esse tipo de comportamento, sendo trivializado, vai, aos poucos, sendo normalizado, ou seja, aceito como algo normal. Ao fim, a pluralidade de ideias se perde, mas não é apenas isso, também se perde a capacidade de se debater democraticamente conteúdos e proposições políticas, econômicas e sociais. A forma de argumentação mais típica do debate nesse cenário é o chamado argumento ad hominem, isto é, quando alguém procura negar uma proposição com uma crítica ao seu autor e não ao seu conteúdo. Quem estuda lógica e argumentação sabe que esse tipo de argumento é falacioso, contudo parece ser cada vez mais utilizado. Ele expressa não apenas a superficialidade do debate e a fragilidade da democracia, mas também uma ausência de respeito ao outro, que deixa de ser entendido como um cidadão ou uma cidadã igualmente cooperante na vida social e política.

A brutal desvalorização do lugar do outro ou a perda da outricidade como referência social e política produz diferentes níveis de negação do outro, dentre eles: a indiferença, a rejeição e a demonização. No caso da indiferença, ocorre uma espécie de invisibilização do outro, em que a pessoa vai se tornando cega àquilo que não lhe interessa, sobretudo a quem não lhe interessa. Frases como "eu não me importo" ou "não estou nem aî..." configuram a legenda da indiferença. O outro pode ser invisibilizado pelo eu indiferente por variados motivos, algumas vezes por pura misantropia, mas, em geral, em função de preconceitos, especialmente o elitismo. ${ }^{4} \mathrm{O}$ segundo nível de negação do outro é a rejeição. Importante esclarecer que não se trata do outro que se sente rejeitado, mas do eu que, de fato, rejeita o outro e não quer estabelecer com ele

\footnotetext{
${ }^{4}$ Aqui vale a lembrança do seguinte trabalho: Costa (2004). Nesse livro, Fernando Braga narra uma interessante experiência que passou ao exercer a tarefa de gari como parte de suas atividades acadêmicas, da graduação à pós-graduação, no Instituto de Psicologia da USP. Nessa experiência pode vivenciar o drama da invisibilidade social.
} 
nenhuma relação que não seja a pura refusa. Aqui o preconceito alcança um tom muito mais elevado. Racismo e misoginia são bons exemplos. No limite, a rejeição transcende o preconceito e se transforma em discriminação. É interessante notar que ainda que existam normas jurídicas as quais combatam e criminalizem a discriminação, ela continua a existir e ser perpetrada e não raro alguém se manifesta para tentar justificá-la no caso concreto. Por fim, o terceiro nível de negação do outro, e o mais extremado, é a demonização. Nesse ponto, o eu vê no outro a encarnação de todo mal, como se ele fosse causa direita ou indireta dos problemas pessoais e sociais mais graves que podem existir. O outro é colocado no lugar de ameaça, e o eu se coloca numa postura passivoagressiva de resistência e ataque. Num ponto como esse, a agressividade para com o outro chega às raias da psicose, até o ponto que a pessoa não consegue enxergar fatos evidentes e nem ouvir argumentos convincentes, ela apenas teme e odeia.

Diante da negação do outro, o eu procura outro eu para se afirmar e fortalecer. Em outras palavras, para avigorar a repulsa ao diferente, há um movimento de agregação do igual, isto é, a cultura de fortalecimento do eu provoca a união de muitos "eus". Há um claro componente narcísico nesse movimento, pois o outro eu funciona como uma espécie de espelho que reforça minha própria imagem. $O$ tipo de agregação a que me refiro não é aquele que se dá pelo compartilhamento de uma identidade entre pessoas que lutam por reconhecimento (HONNETH, 2009), nem mesmo a agregação que ocorre como na forma das tribos pós-modernas que expressam certo modo de vida ou afetos em comum (MAFFESOLI, 1998). Trata-se mesmo de uma agregação narcísica de pessoas que reforçam reciprocamente os seus respectivos egos e o fazem sem nenhuma capacidade de autocrítica, mesmo que tenham de se distanciar da realidade concreta para não serem expostas ao contraditório. Essas pessoas assim unidas entre elas, e afastadas da realidade, tendem a se estruturar em grupos mais ou menos fechados, isto é, aberto a outros, mas desde que dispostos a reforçar o mesmo do grupo. Uma palavra comumente usada para designar esse fenômeno é "bolha".

A sociedade de bolhas é um fenômeno típico da era da internet e das redes sociais. Não que não existisse antes; grupos, clubes, associações e mesmo encontros em casas e bares já expressavam formas de bolhas, porém a ultraconectividade da internet e a facilidade de acesso às redes sociais elevaram a configuração das bolhas a um nível alarmante. Um dado especialmente relevante das bolhas e do debate público nas redes sociais é a falta de mediação e a não visualização do interlocutor. Esse tipo de condição favorece a agressividade da retórica, de modo que muitas pessoas se manifestam de forma desrespeitosa, ríspida e truculenta. É claro que essa forma de manifestação já existia outrora, mas dois elementos já citados tornam o ambiente especialmente assustador e preocupante: 1) a cultura de profundo fortalecimento do ego e de brutal desvalorização da outricidade; e 2) a internet como um novo espaço público sem 
mediação e com alcance virtualmente global. Nesse contexto, ficou muito fácil estar numa bolha e, de dentro dela, promover o repúdio ao outro em larguíssima escala, seja na forma da rejeição, seja na forma da demonização, tudo sem contestação interna. As maneiras mais frequentes e visíveis desse repúdio costumam se dar no discurso de ódio e no asco. Em relação a esse último, ocorre muito que os emojis vomitando sejam usados para se referir às pessoas que pensam diferente dos integrantes da bolha. O ódio e o asco expressam hostilidades e conflagram disputas insanas que aumentam o preconceito e banalizam a discriminação, dando a esses um caráter estrutural. $O$ desentendimento vai se generalizando a tal ponto que as pessoas não conseguem mais enxergar o outro (diferente) como cidadão ou cidadã livre e igual.

Quando tratamos dessa questão no domínio próprio da política, os resultados são especialmente desastrosos e minam as condições de civilidade da sociedade. Desde Aristóteles enfatiza-se que a política é a esfera do comum, sendo o seu maior desafio a busca daquilo que é vantajoso para todos (ARISTÓTELES, 1998, p. 1-6). Em uma sociedade que tem por base um arranjo econômico de tipo capitalista, a ideia do vantajoso para todos já perde muita força diante da primazia da busca dos interesses privados e da fortuna pessoal. Além disso, a lógica concorrencial do mercado faz que o outro seja visto como um competidor, o que, por si só, já favorece muito mais a disputa e a contenda do que a solidariedade e a fraternidade. Quando se soma a isso os processos sociais inflamados pelo egocentrismo e pelo egoísmo que produzem rejeição e demonização do outro, o resultado inevitável é o ódio como forma de fazer política. $\mathrm{O}$ outro é alçado à condição de inimigo, e a política passa a ser vista como guerra, e numa guerra, o objetivo é aniquilar o inimigo. Nesse ambiente belicoso, a esfera do comum própria da política implica estabelecer com o outro uma relação, porém uma relação de destruição.

Os processos de negação do outro possuem na sua base uma cultura de intolerância, ao mesmo tempo em que também produzem práticas intolerantes. Assim, a intolerância funciona, a um só tempo, como causa e consequência desse grave processo social. Ela se apresenta nas bolhas, mas também ocorre fora dela, nas atividades cotidianas. Talvez por isso mesmo, se reproduza tão facilmente nas bolhas, de forma intensificada, pois já ocorre uma tolerância à intolerância desde o cotidiano real. $\mathrm{O}$ fato é que a disposição narcísica que produz o encantamento pelo espelho também gera certa indisposição para os outros. Vejamos Freud (2011, p. 57):

Nas antipatias e aversões não disfarçadas para com estranhos que se acham próximos, podemos reconhecer a expressão de um amor a si próprio, um narcisismo que se empenha na afirmação de si, e se comporta como se a ocorrência de um desvio em relação a seus desenvolvimentos individuais acarretasse uma crítica deles e uma exortação a modificá-los. 
Amar a si mesmo parece ser muito mais fácil e encantador do que amar o outro. Isso se torna plenamente compreensível quando nos damos conta que a primeira inclinação natural de todas as pessoas é maximizar o seu próprio prazer e seus próprios interesses. Porém, reconhecer isso não significa uma adesão automática à moralidade utilitarista. Ainda que concorde com Bentham (1979, p. 3) sobre essa inclinação, isso não quer dizer que maximizar o próprio prazer seja sempre o moralmente correto a se fazer ou mesmo adequado em contextos intersubjetivos. Contudo, é preciso reconhecer certa dificuldade de lidar com as diferenças que decorre desse grande apreço que temos por nós mesmos. Num texto de 1918, chamado O Tabu da Virgindade, Freud cunhou a expressão narcisismo das pequenas diferenças para se referir às dificuldades inatas às relações entre pessoas no cotidiano (FREUD, 2006). Cada pessoa apegada ao seu próprio eu resguarda uma porção do narcisismo que lhe é constitutiva, porém paga-se o preço de identificar no outro uma forma de estorvo, o que cria no indivíduo uma intolerância em relação ao outro diferente. Não é coincidência que a expressão tenha surgido exatamente num texto que trata sobre o tabu da virgindade associada ao corpo feminino. $O$ fato é que a centralidade do mesmo (o igual) nos padrões masculinos que são dominantes nunca soube lidar com qualquer tipo de emancipação da mulher, pois isso implicaria colocar o diferente no nível equivalente ao padrão dominante.

Freud nos mostra que o narcisismo das pequenas diferenças é inevitável nas relações cotidianas e, de certa forma, está na base da constituição do eu porque permite sua afirmação e resguarda sua unidade. Todavia, quando se instaura a ponto de inviabilizar a constituição de uma comunidade ou de um grupamento social, ele expressa uma intolerância que institui não apenas uma incapacidade de lidar com o outro, mas também que inviabiliza a configuração dos limites que são imprescindíveis à formação do sujeito. Essa dimensão, de certa forma patológica, do narcisismo nas pequenas diferenças, encontra sua manifestação mais aguda naqueles processos intersubjetivos de repúdio ao outro que podem ser percebidos na rejeição e na demonização. Na vida social, isso, via de regra, pode ser notado em diferentes formas de preconceito, discriminação e segregação, tais como o racismo, o machismo, a xenofobia e o elitismo. Essas formas de manifestação seriam espécies de paroxismo do narcisismo das pequenas diferenças que dizem respeito não apenas às pessoas que são diretamente afetadas por elas, mas a todas as pessoas da sociedade, pois se liga à própria estrutura da vida política ou, em outras palavras, ao modo como organizamos a sociedade. E qualquer forma de organização social que seja baseada em, ou admita, preconceitos, discriminações e segregações, é definitivamente incompatível com a democracia.

É interessante notar, e isso preocupava Freud, como é possível acontecer diferentes maneiras de uma brutal manipulação da intolerância ao outro. $\bigcirc$ narcisismo das pequenas diferenças existe, isso é um fato, mas ele não precisa ser exacerbado ao 
ponto de inviabilizar uma comunidade social e muito menos, ao ponto de gerar diferentes formas de preconceito, discriminação e segregação. Se isso ocorre é porque há centros de poder que se beneficiam desse acontecimento ou desse arranjo. Esses centros de poder que atuam com base na força e manipulam pessoas e instituições podem estar vinculados a diferentes tipos de interesse, como, econômico, político ou cultural. $\mathrm{O}$ poder econômico é o mais visível nas sociedades capitalistas, pois decorre da apropriação de recursos, da acumulação do capital e da exploração do trabalho alheio, sobretudo na forma da mais-valia. Porém, para que ele se mantenha em sociedades democráticas, é preciso convencer a grande maioria da sociedade que o enriquecimento de alguns é bom para todos. Isso é feito, em geral, pela manipulação das informações e dos sonhos. Tratase de fazer acreditar que, por meio exclusivo do esforço pessoal, do mérito próprio, qualquer indivíduo pode obter o acúmulo de riqueza. Nesse momento é que as mentes dissonantes e que se posicionam contra isso são taxadas como os "diferentes", isto é, constituem uma outricidade marcada por rótulos que produzem inferiorização social, tais como "perdedor", "preguiçoso" ou "incompetente". O elitismo é uma forma frequente de preconceito que ocorre pela manipulação do poder econômico. Até mesmo os mais empobrecidos não estão imunes à manipulação que gera o elitismo, pois o fato de enfrentarem privações não os impede de acreditar que o estilo de vida e a forma de pensar das elites seria o correto para todos, inclusive eles.

Outro centro de poder que atua com base na força e manipula pessoas e instituições é o poder político. Enquanto o poder econômico está baseado na riqueza e na força do capital, o poder político costuma se apoiar no controle das instituições estatais e na força da influência política. Como dito, o grande centro do poder político, sem dúvida, é o estado, em especial os órgãos de governo. A partir deles, os grupos dominantes da política concentram seu poderio para se perpetuarem o mais possível no controle desses órgãos. É comum se associar o poder político aos políticos profissionais, ou seja, aos que ocupam mandatos eletivos no executivo e no legislativo. Essa associação não está errada, mas o poder político também é exercido por outros setores do estado, como o judiciário e o Ministério Público. Um exemplo claro são as práticas de lawfare (KITTRIE, 2016) que ocorrem no sistema de justiça. Vale ter em mente que todo o aparato de estado, inclusive do sistema de justiça, pode ser utilizado conforme o interesse de seus integrantes.

Por fim, a cultura também pode ser um centro de poder que manipula pessoas e instituições. Aqui, por cultura, pretendo dizer um conjunto de padrões de comportamento, crenças e costumes que distinguem um grupo social. Algumas crenças e costumes de uma comunidade podem desafiar conquistas civilizatórias, como a liberdade e a igualdade, e não reconhecer as formas de viver e as práticas sociais que são diferentes do padrão dominante. No mais das vezes, isso enseja uma espécie de 
hierarquia de identidades que subordina certos segmentos sociais aos grupos dominantes da cultura. O sexismo e o racismo são exemplos muito evidentes dessa forma de manipulação por parte de setores hegemônicos apoiados pela cultura. É importante que se tenha claro que essa distinção entre poder econômico, político e cultural possui, sobretudo, natureza heurística, para que se faça uma análise mais cuidadosa das manipulações praticadas pelo poder, como preocupava a Freud. Entretanto, na vida real, todos esses centros de poder se sobrepõem e podem atuar de forma a produzir uma manipulação que se vale do narcisismo das pequenas diferenças para gerar processos violentos e atrozes de intolerância ao outro e às diferenças, esvaziando a democracia e valendo-se desses processos para aumentarem o próprio poder.

As críticas aqui formuladas em relação aos impactos negativos da cultura de fortalecimento do ego na vida democrática não implicam uma visão utópica ou idealista de democracia, como se não houvesse outros problemas caso não existisse tanto egocentrismo e egoísmo no mundo atual. Como foi dito antes, a democracia é em si mesma problemática e desafiadora em vários aspectos e precisará sempre ser aperfeiçoada conforme as condições concretas de cada momento histórico. O que se sustenta, então, é que a cultura de fortalecimento do ego, o desprezo pela outricidade e a falta de respeito pelo pluralismo razoável agravam as dificuldades e os limites da democracia. Por exemplo, já não basta que o sistema econômico corrompa a democracia para convertê-la em plutocracia, com a crescente falta de empatia, isso é feito sob a indiferença de boa parte da população em relação ao sofrimento que esse processo causa nas pessoas mais empobrecidas. Qualquer concepção não capturada pelo puro idealismo sabe que a democracia necessariamente enseja debates e que as divergências são inatas a ela; mais do que isso: a ilusão de um consenso tende a enfraquecer a vitalidade do debate democrático e pode ser, por isso mesmo, um perigo para a própria política democrática. Todavia, e por outro lado, capturar a democracia numa realidade política em que o outro é visto com indiferença ou é rejeitado e tomado como uma ameaça a ser destruída, significa inviabilizar a própria democracia.

\section{DEMOCRACIA AGONÍSTICA E O OUTRO COMO ADVERSÁRIO E NÃO COMO INIMIGO}

Para se ter uma melhor compreensão da questão, vale recordar o conceito do político que nos foi oferecido por Carl Schmitt ao afirmar que a vida política é marcada pelos elementos polares amizade e guerra. Por isso, para ele, o critério que funda o político como campo próprio e autônomo é a distinção amigo-inimigo. Nas palavras do autor: a distinção especificamente política a que podem reportar-se as ações e os motivos politicos 
é a discriminação entre amigo e inimigo (SCHMITT, 1992, p. 51). Segue Schmitt (1992, p. 52) esclarecendo que:

A diferenciação entre amigo e inimigo tem o sentido de designar o grau de intensidade extrema de uma ligação ou separação, de uma associação ou dissociação; ela pode, teórica ou praticamente, subsistir sem a necessidade do emprego simultâneo das distinções morais, estéticas, econômicas ou outras.

Essa concepção ultrarrealista sustentada por Schmitt escancara a hostilidade com o diferente como forma de fazer política. O inimigo, explica Schmitt, não é definido necessariamente por razões morais, estéticas ou econômicas, embora até possa sê-lo. $\mathrm{O}$ inimigo é basicamente o outro, que pela sua alteridade institui uma diferença irreconciliável e que não pode ser resolvida por normas preexistentes nem pelo veredito de um terceiro desinteressado (SCHMITT, 1992, p. 52). A figura do estrangeiro é especialmente importante para Schmitt, pois encarnaria uma diferença existencial que exigiria de cada pessoa interessada um posicionamento refletido e individual:

[...] cada um deles [interessados] tem de decidir por si mesmo, se a alteridade do estrangeiro, no caso concreto do conflito presente, representa a negação de sua própria forma de existência, devendo, portanto, ser repelido e combatido, para a preservação da própria forma de vida, segundo sua modalidade de ser (SCHMITT, 1992, p. 52).

Chega a ser chocante essa maneira crua e direta como Schmitt situa o outro na condição de ameaça ao eu (o mesmo) nessa esfera do político. Daí resulta a necessidade de uma decisão: esse outro é meu amigo ou meu inimigo? A resposta surge como algo intuitivo: se é fonte de ameaça, então é meu inimigo. Assim, a diferença marca a divisão de territórios políticos e, em alguns casos, de territórios geográficos. ${ }^{5}$ Porém não é só isso, a alusão ao estrangeiro como referência de outricidade abre as portas da política para a ideia de guerra e as violências que lhe são inerentes. Sobre isso, Schmitt explica que a guerra não é, absolutamente, fim e objetivo, sequer conteúdo da política, porém é o pressuposto sempre presente como possibilidade real, a determinar o agir e o pensar humanos de modo peculiar, efetuando assim um comportamento especificamente político (SCHMITT, 1992, p. 60). Em outras palavras, a política assim concebida é guerra, não porque debata sobre a guerra, mas porque define o comportamento das pessoas envolvidas no sentido de

\footnotetext{
${ }^{5}$ Sen (2000, p. 22-23) narra um caso que testemunhou quando criança na cidade indiana onde morava com sua família. Um homem muçulmano precisou aceitar um emprego de diarista num bairro dominado por hindus. Mesmo sabendo dos riscos, ele aceitou o emprego numa área hostil porque já não tinha mais como alimentar sua família. Como resultado por transitar naquela área, o homem muçulmano foi esfaqueado e morto por homens hindus. Nessa história, fica claro como a diferença demarcou não apenas territórios políticos, mas também territórios geográficos onde o inimigo pode ser aniquilado.
} 
pretender aniquilar o inimigo. Entretanto, diferentemente da guerra convencional, em que o inimigo é outro povo, na política como guerra, o inimigo pode ser alguém que está ao seu lado, um concidadão, uma pessoa que, em tese, deveria ser considerada tão livre e igual como você. Essa guerra interna levada a cabo nesse sentido da política de que nos fala Carl Schmitt se assenta sobre o repúdio ao outro tomado como alteridade fora do padrão e, por isso, ameaçadora. Todavia, não se restringe apenas às questões que possam ser entendidas como existenciais - diferentes modos de ser -; essa guerra interna pode ter motivações ideológicas, até mesmo porque o mundo político é fundamentalmente marcado pelas discrepâncias ideológicas. Mesmo tratando-se de divergências na política interna, ainda assim, Schmitt admite a possibilidade de confrontos reais que assumem os contornos de uma guerra:

Quando no interior do Estado os antagonismos político-partidários transformam-se completamente "nos" antagonismos políticos, alcança-se o grau extremo na escala da "política interna", ou seja, agrupamentos amigoinimigo infra-estatais, não de política externa, são os decisivos para o confronto armado (SCHMITT, 1992, p. 58).

Para Schmitt, esse confronto armado é visto como guerra civil, mas a história já nos ensinou que as práticas fascistas, mesmo sem guerra civil, valem-se de milícias civis e formas violentas para ameaçar, amedrontar e, no limite, matar aqueles que pensam diferente. $^{6} \mathrm{O}$ fascista recorre a mitos fundantes da pátria, como as ideias de nação e orgulho patriótico, para perseguir e calar seus inimigos. Utiliza-se de chavões como lei e ordem e propagandeia seus ideais conservadores gerando ódio e desprezo pelos que não comungam de suas ideias; apresenta-se como a única alternativa verdadeiramente íntegra diante de um ambiente corrompido. Assim, o fascista pretende fazer acreditar que quem pensa diferente dele não é uma pessoa humana, mas o próprio mal encarnado (demonização do outro). O resultado disso é o que Schmitt denominou de "grau extremo na escala da política interna”, ainda que não seja declarada uma guerra civil, como tradicionalmente conhecida.

O pensamento de Carl Schmitt provocou muitas polêmicas ao longo do século XX, especialmente porque seu livro O Conceito do Político foi publicado em 1932, e, com a ascensão do Terceiro Reich em 1933, Schmitt passou a ser considerado uma espécie de iminência parda em alguns grupos nazistas, embora nunca tenha ocupado nenhum cargo importante no próprio Partido Nazista; aliás, ele teve muitos problemas com lideranças influentes do Partido a partir de 1936 e foi banido de várias atividades a partir de 1937 (MEHRING, 2014). Porém, a verdade é que a ideia de se pensar o

\footnotetext{
${ }^{6}$ Em relação às práticas fascistas, vejam-se os importantes trabalhos: Konder (2009), Stanley, (2018) e Eco (2018).
} 
político a partir da distinção amigo-inimigo pareceu ser propícia à política nazista, especialmente na perseguição aos judeus, uma vez que a judeidade foi apontada como a antítese do ideal de homem ariano (FUCKS, 2000). No plano propriamente intelectual, o pensamento schmittiano sofreu críticas tanto de autores da direita liberal quanto da esquerda, dado o seu caráter conservador. Contudo, a dimensão não idealista do conceito do político formulado por Carl Schmitt chamou a atenção de Chantal Mouffe para uma perspectiva mais realista e concreta sobre a política, especialmente propicia para a crítica da democracia liberal. Em artigo originalmente publicado em 1997 no Canadian Journal of Law $\mathcal{G}$ Jurisprudence, intitulado Carl Schmitt and the Paradox of Liberal Democracy, Mouffe (2012, p. 53-54) afirma que o confronto com o pensamento de Carl Schmitt permite reconhecer um importante paradoxo inscrito na natureza da democracia liberal. O argumento central de Mouffe é que aquilo que os modernos chamam de democracia ou revolução democrática resulta de duas tradições distintas que não possuem nenhuma conexão conceitual, apenas uma ligação histórica contingente. A primeira é a tradição liberal que afirma o império da lei e a defesa dos direitos individuais, com ênfase na liberdade. A segunda é a tradição democrática que afirma a soberania popular e a identidade entre governantes e governados, com ênfase na igualdade. $O$ paradoxo consiste no fato de que essas tradições obedecem a lógicas distintas e, por isso seria impossível conciliá-las de forma perfeita (MOUFFE, 2012, p. 20-22).

Segundo Mouffe (2012, p. 65-72), a maneira pela qual Schmitt compreende o político revela o paradoxo da democracia, pois, na medida em que a ação política é sempre matizada pelo binômio amigo-inimigo, o conflito visceral se torna inevitável, e isso expressa a impossibilidade de haver consensos de tipo liberal na democracia, pois eles são por demais provisórios e volúveis. Mouffe concorda com Schmitt que a democracia implica um sentido forte da ideia de povo - demos - que a perspectiva parlamentar típica da tradição liberal não comporta, por isso consensos parlamentares são frágeis e tendem a não expressar o modo de ser de um grupo social. Todavia, Mouffe discorda de Schmitt de que a unidade espiritual de um povo acabaria com os antagonismos da política porque excluiria os diferentes, os inimigos. Assim, Mouffe reafirma uma ideia que já vinha sustentando desde a publicação de Hegemony and Socialist Strategy: Towards a Radical Democratic Politics, escrito com Ernesto Laclau, em 1985. Trata-se de uma concepção agonística de democracia que parte das premissas de que é preciso resgatar a ideia de povo (pois o individualismo extremo é uma ameaça ao tecido social) e que é preciso dar ênfase nas práticas sociais (e não apenas na razão abstrata que fundamenta as instituições). A partir daí, sustenta que o poder é constitutivo das relações sociais, já que todas as pessoas e grupos envolvidos em relações políticas sempre pretendem agir de forma a tornar sua influência preponderante. A 
busca por hegemonia é o lado objetivo do poder no âmbito da política democrática. Isso implica considerar o conflito como algo inerente à democracia, de modo que as iniciativas que pretendem negar o conflito devem ser vistas como ameaçadoramente totalitárias: "o caráter democrático de uma sociedade só pode ser dado pelo fato de que nenhum ator social limitado pode pretender representar o todo e afirmar que tem "controle" sobre os fundamentos" (MOUFFE, 2012, p. 113).

Chantal Mouffe denomina seu modelo de democracia agonística de pluralismo agonístico. Assim como faz Schmitt, Mouffe também parte da ideia de um inevitável antagonismo no âmbito do político. Porém, há uma diferença fundamental entre ambos. Vejamos: Schmitt (1992, p.55-56) afirma que "o antagonismo político é a mais intensa e extrema contraposição e qualquer antagonismo concreto é tanto mais político quanto mais se aproximar do ponto extremo, do grupamento amigo-inimigo." Portanto, o que define o antagonismo para esse autor é a relação amigo-inimigo. Por seu turno, Mouffe (2012, p. 124) reconhece que o antagonismo é inerente às relações humanas e pode surgir em distintos tipos de relações sociais, mas afirma:

\begin{abstract}
Acredito que somente quando reconhecermos a dimensão do "político" e entendermos que a "política" consiste em domar a hostilidade e tentar atenuar o potencial antagonismo que existe nas relações humanas, poderemos levantar o que considero ser a questão central da democracia política... A política propõe a criação da unidade em um contexto de conflito e diversidade; está sempre relacionado com a criação de um "nós" pela determinação de um "eles". A novidade da política democrática não é a superação dessa oposição nós / eles - o que é uma impossibilidade - mas a forma diferenciada como ela se coloca. A questão crucial é estabelecer essa discriminação entre nós e eles de uma forma que seja compativel com a democracia pluralista.
\end{abstract}

Para estabelecer essa diferença entre nós e eles de forma compatível com a democracia pluralista, Mouffe propõe reconstruir a ideia de "eles" de forma que esse outro deixe de ser compreendido como inimigo a ser destruído e passe a ser concebido como um adversário, isto é, como alguém cujas ideias eu posso combater, mas sem que eu possa colocar em dúvida o direito dele a ter essas ideias. Essa concepção conflitiva de democracia possui a vantagem de ser mais realista e menos idealizada, mas não renuncia a um fundamento moral, pois compreende que o adversário é alguém a quem me ligo no âmbito da política democrática e, por conseguinte, a quem estou unido na consideração pelos valores da liberdade e da igualdade, ainda que possamos ter entendimentos distintos acerca de como esses valores devem ser postos em prática (MOUFFE, 2012, p. 115).

É importante notar como o pluralismo agonístico de Chantal Mouffe se opõe às práticas políticas centradas no $\mathrm{eu}$, pois implica necessariamente o reconhecimento de outro que possui ideias próprias e com o qual eu devo dialogar, ainda que em debate vigoroso, se pretendo participar das lutas por hegemonia. $O$ outro, para que mantenha

98• R. Opin. Jur., Fortaleza, ano 20, n. 33, p.83-102, jan./abr. 2022 
essa condição fundamental, não está para ser assimilado ou rejeitado, muito menos destruído, mas é alguém com o qual eu devo lidar respeitosamente e preservar sua liberdade e igualdade, para que a liberdade e a igualdade mesmas, que são os fundamentos morais da democracia, não se percam. Considerar o outro que pensa diferente de mim como adversário, e não como inimigo, é a atitude ética elementar da política democrática. Nesse sentido, Mouffe se desvincula de Schmitt e propõe entender o antagonismo político como agonismo, ou seja, como uma luta entre adversários e não entre inimigos. Nas palavras da autora: "isso pressupõe que o "outro" não é visto mais como um inimigo a ser destruído, mas como um adversário, ou seja, alguém com cujas ideias vamos lutar, mas cujo direito de defender essas ideias não iremos questionar.” (MOUFFE, 1999, p. 755). Para transformar antagonismo em agonismo, afirma que é necessário proporcionar canais por intermédio dos quais as pessoas possam se identificar em identidades comuns e paixões coletivas, mas sem que isso construa o oponente como inimigo e coloque em risco a própria democracia. Assim explica Mouffe (1999, p.755756):

...o modelo de pluralismo agonístico que eu estou defendendo afirma que a tarefa primordial da política democrática não é eliminar as paixões e nem as relegar à esfera privada para tornar o consenso racional possível, mas mobilizar estas paixões na direção da promoção de projetos democráticos. Longe de ameaçar a democracia, o confronto agonístico é, de fato, sua verdadeira condição de existência.

Essa concepção do pluralismo agonístico leva a sério a presença do outro que é irredutível ao eu (mesmo), pois coloca a outricidade como a base fundante da vida política numa democracia. Isso exige que se reconheça uma série de elementos que são típicos da alteridade, tais como: eu não sou o centro da ação política, pois, como atividade relacional, ela somente é possível em função da existência de outro; a busca pela hegemonia é típica da ação política, e isso vale tanto para a mim quanto para o outro; a luta política somente é legítima quando não é indiferente ao outro e quando toma o outro que pensa diferente como adversário que deve ser respeitado e não como inimigo a ser rejeitado ou aniquilado; as divergências e os desentendimentos com os adversários devem ser tratadas dentro dos mecanismos legítimos da ação política, abertos igualmente a todos; nas democracias, os argumentos dos opositores devem ser combatidos e não as pessoas, argumentos ad hominem, além de falaciosos, são incompatíveis com a importância do outro para uma democracia.

Mouffe (2012, p. 117) afirma que uma democracia que funcione corretamente exige um vibrante enfrentamento de posições políticas democráticas. De saída, isso implica um esforço sincero de superação do narcisismo das pequenas diferenças na vida política, pois é exatamente aqui que ele se converte em paroxismo e descamba na forma de preconceitos violentos, discriminação e exclusão, dando ensejo a tais práticas de 
forma estrutural. Quem pretende fazer política não pode se dar ao desfrute da falta de civilidade; e o respeito e a boa educação não devem ser confundidos com cinismo ou conivência, antes eles denotam compromisso com o pluralismo razoável. Práticas como a do escracho - humilhação do outro em ambiente público - precisam ser entendidas como inaceitáveis porque deslocam o alvo das ideias para as pessoas, por isso mesmo eram comuns na Alemanha nazista e nos territórios ocupados. Além disso, o enfrentamento vibrante de políticas democráticas é absolutamente incompatível com as práticas fascistas, pois o fascismo é totalitarista e pretende aniquilar o outro. Os métodos fascistas pregam o ódio, demonizam o outro, manipulam as instituições, se valem de mentiras, destroem reputações, perseguem o diferente e se utilizam de violência física para calar os que não comungam das mesmas ideias.

Nessa mesma linha, o reconhecimento do pluralismo agonístico com a devida outricidade e a busca legítima por hegemonia, não são compatíveis com formas de pensar e com modos de viver que sejam fundados sobre a intolerância e a perseguição ao diferente. Vale notar que, em respeito à democracia, as diferenças devem ser toleradas, menos aquelas que sustentem a intolerância, que tomem o outro como inimigo a ser conquistado ou aniquilado. Isso significaria a negação da outricidade que fundamenta o próprio pluralismo agonístico ou qualquer concepção política que se pretenda democrática. Portanto, quando dito anteriormente que, no âmbito do pluralismo agonístico, o adversário não é inimigo, mas alguém cujas ideias eu posso combater, sem, por isso, colocar em dúvida seu o direito a ter essas ideias, isso vale até o ponto em que tais ideias não se enquadrem nas perspectivas do fascismo, do totalitarismo e daquelas formas intolerantes que pretendem silenciar, excluir ou aniquilar as diferenças. Isso porque esse tipo de pensamento ou de atitude já extrapola a moldura democrática e institui o ódio como forma de fazer política.

\section{CONSIDERAÇÕES FINAIS}

Uma política que não se renda ao egocentrismo e ao narcisismo e que, nesse mesmo passo, não entenda o outro diferente como inimigo a ser destruído, não pode ser considerada pretensão ingênua ou uma meta inatingível. Ela revela a importância da responsabilidade como base do fazer político e uma esperança de manter a política para além do egoísmo, da indiferença e do ódio. Por seu turno, essa responsabilidade no âmbito do político implica uma política sempre interpelada pela ética, provocada nas suas pretensões e interrogada quanto aos meios que propõe. Uma política convidada tanto a se comprometer com os valores morais que são constitutivos da democracia, como a liberdade e a igualdade, quanto com os princípios que estruturam o próprio 
jogo democrático, como a permanente possibilidade de contestação e a necessária interdependência.

Isso implica um esforço para não se deixar levar pela cultura de fundo extremamente individualista e recuperar o valor de espaços e bens em comum, para além do inevitável "nós" e "eles" que é parte da vida democrática. Todavia, e por outro lado, também envolve um esforço de agentes e instituições da política em se oporem vigorosamente a todas as formas de práticas políticas que imponham ou admitam discursos tão tóxicos e intolerantes ao ponto de produzir ou compactuar com o ódio ao diferente como forma de fazer política. Nenhuma forma de fazer política deve conduzir à degradação do outro ou impedir que o outro apresente suas demandas legítimas.

\section{REFERÊNCIAS}

ARMONY, Ariel; SCHAMIS, Hector. Babel in Democratization Studies. Journal of Democracy, v. 16, n. 4, 2005.

ARISTÓTELES. A Política. São Paulo: Martins Fontes, 1998.

BENTHAM, Jeremy. Uma Introdução aos Princípios da Moral e da Legislação. São Paulo: Abril Cultural, 1979.

COSTA, Fernando Braga da. Homens Invisíveis: relatos de uma humilhação social. São Paulo: Globo, 2004.

ECO, Umberto. O Fascismo Eterno. Rio de Janeiro: Record, 2018.

FREUD, Sigmund. El tabú de la virgindad. Buenos Aires: Amorrortu, 2006.

FREUD, Sigmund. Psicologia das massas e análise do eu. São Paulo: Companhia das Letras, 2011.

FUCKS, Betty. Freud e a judeidade: a vocação do exílio. Rio de Janeiro: Zahar, 2000.

HAN, Byung-Chul. Sociedade do Cansaço. Petrópolis: Vozes, 2015.

HAN, Byung-Chul. Topologia da Violência. Petrópolis: Vozes, 2017.

HELD, David. Democracy and the global order: from the modern state to cosmopolitan governance. California: Stanford University Press, 1995.

HONNETH, Axel. Luta por Reconhecimento. A gramática moral dos conflitos sociais. São Paulo: Editora 34, 2009.

KITTRIE, Orde F. Lawfare: Law as a Weapon of War. New York: Oxford University Press, 2016. 
KONDER, Leandro. Introdução ao fascismo. São Paulo: Expressão Popular, 2009.

LÉVINAS, Emmanuel. Humanismo do outro homem. Petrópolis: Vozes, 2012.

MAFFESOLI, Michel. O Tempo das Tribos: o declínio do individualismo nas sociedades de massa. Rio de Janeiro: Forense Universitária, 1998.

MEHRING, Reinhard. Carl Schmitt: a biography. New York: Polity, 2014.

MOUFFE Chantal. La Paradoja Democrática: el peligro del consenso en la política Contemporánea. Barcelona: Editorial Gedisa, 2012.

MOUFFE, Chantal. Deliberative Democracy or Agonistic Pluralism? Social Research, v. 66, n. 3, 1999.

PAXTON, Marie. Agonistic Democracy: Rethinking Political Institutions in Pluralist Times. New York: Routledge, 2020.

PRZEWORSKI, Adam. Crises of Democracy. Cambridge: Cambridge University Press, 2019.

ROUANET, Sérgio Paulo. Mal-Estar na Modernidade. São Paulo: Cia das Letras, 1993.

SCHMITT, Carl. O Conceito do Político. Petrópolis: Vozes, 1992.

SEN, Amartya. Desenvolvimento como Liberdade. São Paulo: Companhia das Letras, 2000 .

STANLEY, Jason. How Fascism Works: The Politics of Us and Them. New York: Random House, 2018.

TAYLOR, Astra. Democracy May Not Exist, but We'll Miss It When It's Gone. New York: Metropolitan Books, 2019.

TOURAINE, Alain. Crítica da Modernidade. Petrópolis: Vozes, 1994.

Como citar este documento:

CUNHA, José Ricardo. Democracia agonística por oposição ao narcisismo político: contra o ódio como forma de fazer política. Revista Opinião Jurídica, Fortaleza, v. 20, n. 33, p. 83-102, jan./abr. 2022. 